\title{
Serum enzyme variations and histological abnormalities in the carrier state in Duchenne dystrophy ${ }^{1}$
}

\author{
JAMES STEPHENS AND EDWARD LEWIN \\ From the Division of Neurology, University of Colorado Medical Center, and the Veterans Administration \\ Hospital, Denver, Colorado, U.S.A.
}

It is generally agreed that the Duchenne form of muscular dystrophy is transmitted as a sex-linked recessive trait with a high mutation rate. The female may be a carrier, but the clinical manifestations of the disease will be limited to males. The occasional expression in the female has been explained by either autosomal recessive inheritance (Dubowitz, 1960) or the mating of a carrier female with a male from whom the X-chromosome has been eliminated during the process of fertilization, giving rise to an $\mathrm{X}-\mathrm{O}$ female (Walton, 1956).

More recently Lyon's hypothesis of X-chromosome mosaicism has been suggested as an explanation for the occurrence of minor clinical features of the disease in female carriers (Emery, 1963; Pearson, Fowler, and Wright, 1963). Lyon (1961) proposed that in all female mammalian somatic cells one Xchromosome became inactive early in embryonic life, that in any given cell this might be the paternal or maternal X-chromosome, and that the descendents of this cell would have the same genetic characters. If this hypothesis be true, then in the female carrier of Duchenne dystrophy, any individual muscle fibre might be normal if its characteristics were determined by the normal paternal X-chromosome or dystrophic if determined by the abnormal maternal $\mathrm{X}$-chromosome. Thus, the carrier would have two populations of muscle fibres, normal and dystrophic, and whether or not there were clinical manifestations of the disease would depend on the proportion of dystrophic fibres.

It is known that there is markedly increased activity of a number of enzymes in the serum of patients with Duchenne dystrophy, particularly creatine phosphokinase. Supposedly, in this condition, the muscle membrane is altered, allowing the intracellular enzymes to leak into the serum (Thomson, 1962). The demonstration of elevated serum enzyme levels in the predystrophic stage of affected males

'This work was supported by the Martin J. and Mary Anne O'Fallon Fund, the N.I.H. Clinical Center No. FR 00051 and the Continuing Research Fund of the University of Colorado.
(Pearson, 1962) and in female relatives of dystrophic males (Richterich, Rosin, Aebi, and Rossi, 1963; Hughes, 1963; Pearce, Pennington, and Walton, 1964b) suggests that in these the muscle membrane is similarly altered. Further Pearson et al. (1963) have shown that in three female siblings with elevated serum creatine phosphokinase levels there were minimal changes in isolated muscle fibres, although i there were no clinical abnormalities. The identifica in tion of the carrier state would then depend on the demonstration of a population of dystrophic muscie fibres, either directly by histological examination o 0 을 inferentially by measurement of serum creatine phosphokinase activity.

Previous studies have not yet defined whether the creatine phosphokinase activity changes wit $\vec{k}$ exercise. That it might be elevated following severe of exercise was suggested by Richterich et al. (1963) although Hughes (1963), and Pearce, Pennington, and Walton (1964a) have indicated that there is no significant change. Since one might anticipate that there would be an increase with exercise, in the present study the level of creatine phosphokinase activity was estimated after a period of rest, immediately after moderately severe exercise, and serially for the next 24 hours. Random observations were made during normal daily activities.

\section{MATERIAL AND METHODS}

There were four mothers of males with Duchenne $\overline{0}$ dystrophy in this study. Of these four, one was a definite 3 . carrier, i.e., with an affected son and an affected brother; $\delta$ two were probable carriers, i.e., with two or more affected 3 sons but with no male siblings or uncles affected; one was a possible carrier, i.e., with one affected son and no other affected male relatives. Physical examination was normal $D$ in all cases. In addition, nine healthy young females without a family history of muscle disease were tested $N$ to establish the norm in our laboratory. Random samples 5 were taken from a further 10 young women.

TEST PROCEDURE Blood samples for estimation of $N_{\omega}$ creatine phosphokinase activity were taken before rising 
in the morning after at least 10 hours of rest in bed. Exercise consisted of walking for one hour at three miles per hour up an $8 \%$ incline. Serial samples were taken immediately after the exercise and as nearly as possible, two, five, and 24 hours later. The 24-hour specimen followed 10 hours of strict bed rest. Random samples were taken in the afternoon of a normal working day. A biopsy of the gastrocnemius muscle was taken in three of the four mothers of patients with Duchenne dystrophy. Serial sections were cut at $5 \mu$ intervals and stained alternately with haemotoxylin and eosin and picroponceau in blocks of five.

SERUM CREATINE PHOSPHOKINASE METHOD Serum creatine phosphokinase activity was estimated using a slight modification of the method of Ebashi (Ebashi, Toyokura, Momoi, and Sugita, 1959; Okinaka, Kumagai, Ebashi, Sugita, Momoi, Toyokura, and Fujie, 1961). This method utilizes the 'backward reaction', i.e., the formation of creatine phosphate from creatine and A.T.P. is measured. The resulting creatine phosphate is determined as phosphate following hydrolysis in an acid molybdate solution at room temperature for 30 minutes. Hydrolysis of creatine phosphate is complete while A.T.P. and A.D.P. undergo minimal breakdown under these conditions (Ennor and Stocken, 1948).

Two incubation media were used. Solution no. 1 contained $0.024 \mathrm{M}$ creatine, $0.002 \mathrm{M} \mathrm{Na}$ ATP, $0.006 \mathrm{M}$ $\mathrm{MgSO}_{4}$, and $0.096 \mathrm{M}$ tris (hydroxymethyl) aminomethane adjusted to $\mathrm{pH} 9 \cdot 0$. Solution no. 2 was similar to no. 1 except that creatine was omitted. For each determination, a pair of tubes containing $0.9 \mathrm{ml}$. of solutions no. 1 and no. 2 , respectively, were preheated in a $37^{\circ} \mathrm{C}$. bath. Duplicate determinations were carried out on each serum. Serum, $0 \cdot 1 \mathrm{ml}$., was added to each of the pair of tubes, and the tubes were returned to the bath. After 30 minutes, the reaction was stopped by adding $0.2 \mathrm{ml}$. of $50 \%$ trichloroacetic acid, and the tubes were promptly centrifuged. An aliquot from the supernatant of each tube was transferred to a separate tube containing a sulphuric acid-molybdate solution. This solution was prepared so that the final concentrations after addition of the aliquot were the same as those employed in the Martin and Doty (1949) procedure for phosphorus determination $(0.8 \mathrm{~N}$ $\mathrm{H}_{2} \mathrm{SO}_{4}$ and $1 \%$ ammonium molybdate). These tubes were allowed to remain at room temperature for 30 minutes in order to hydrolyze any creatine phosphate present. A phosphorus analysis was then performed using an adaptation of the Martin and Doty method. For each sample, the difference in inorganic phosphorus between solutions no. 1 and no. 2 after incubation and hydrolysis was taken to be equivalent to the amount of creatine phosphate formed. The correction suggested by Ebashi et al. (1959) was not used. Results were expressed in international units, i.e., $\mu \mathrm{M}$ substrate $/$ minute $/ 1,000 \mathrm{ml}$. serum.

\section{RESULTS}

Table I shows the results of a random sampling from 10 normal young women during daily activity. Table II shows the serial estimations of creatine phosphokinase activity in healthy young women. There is no significant effect of rest or exercise.

Table III gives the results of the test procedure on

TABLE I

RANDOM SAMPLES FROM 10 NORMAL YOUNG WOMEN

$\begin{array}{lr}\begin{array}{l}\text { Case } \\ \text { No. }\end{array} & \begin{array}{c}\text { Serum Creatine } \\ \text { Phosphokinas }\end{array} \\ \text { G.R.P. } & 0 \cdot 8 \\ \text { C.L.N. } & 0 \cdot 0 \\ \text { D.McG. } & 1 \cdot 5 \\ \text { D.K. } & 1 \cdot 8 \\ \text { D.D. } & 3 \cdot 1 \\ \text { J.R. } & 2 \cdot 5 \\ \text { A.R. } & 0 \cdot 8 \\ \text { S.S. } & 0 \cdot 8 \\ \text { B.L. } & 0 \cdot 0 \\ \text { S.T. } & 0 \cdot 0\end{array}$

Mean 1.1 i.u.

Standard deviation $\pm 1 \cdot 0$ i.u.

TABLE II

CREATINE PHOSPHOKINASE ACTIVITY BEFORE AND AFTER EXERCISE IN NORMAL YOUNG WOMEN

Creatine Phosphokinase Levels (i.u.)

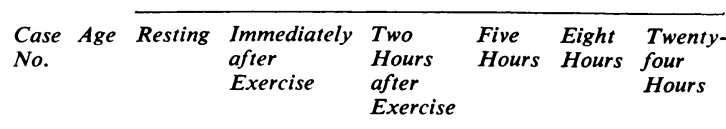

\begin{tabular}{|c|c|c|c|c|c|c|c|}
\hline 1 & 23 & 0.0 & $2 \cdot 2$ & 0.5 & $2 \cdot 4$ & 0.5 & 0.0 \\
\hline 2 & 25 & $2 \cdot 8$ & $3 \cdot 1$ & 0.0 & $2 \cdot 8$ & $5 \cdot 5$ & $6 \cdot 2$ \\
\hline 3 & 25 & 0.0 & $4 \cdot 0$ & 3.9 & 6.5 & $2 \cdot 5$ & $4 \cdot 4$ \\
\hline 4 & 23 & 0.8 & 0.0 & 5.0 & 1.5 & $6 \cdot 2$ & 1.0 \\
\hline 5 & 24 & 0.5 & 0.5 & $2 \cdot 0$ & 0.3 & 0.0 & 0.0 \\
\hline 6 & 24 & 0.0 & $2 \cdot 3$ & $2 \cdot 8$ & 0.0 & $2 \cdot 6$ & 0.5 \\
\hline 7 & 23 & 0.0 & 0.5 & 0.3 & 0.0 & 0.0 & 1.0 \\
\hline 8 & 22 & 0.3 & 0.8 & 0.5 & 0.0 & 0.3 & $0 \cdot 3$ \\
\hline 9 & 24 & 0.0 & 0.0 & 0.0 & 0.0 & 3.8 & 0.0 \\
\hline
\end{tabular}

TABLE III

SERUM CREATINE PHOSPHOKINASE LEVELS IN FOUR MOTHERS OF MALES WITH DUCHENNE DYSTROPHY Creatine Phosphokinase Levels (i.u.)

\begin{tabular}{|c|c|c|c|c|c|c|c|}
\hline Case & Carrier & Random & Resting & $\begin{array}{l}\text { Immediately } \\
\text { after } \\
\text { Exercise }\end{array}$ & $\begin{array}{l}\text { Two to Four } \\
\text { Hours after } \\
\text { Exercise }\end{array}$ & $\begin{array}{l}\text { Five to Seven } \\
\text { Hours after } \\
\text { Exercise }\end{array}$ & $\begin{array}{l}\text { Twenty-four } \\
\text { Hours after } \\
\text { Exercise }\end{array}$ \\
\hline $\begin{array}{l}\text { Fe. } \\
\text { Sch. } \\
\text { Gu. } \\
\text { Ru. }\end{array}$ & $\begin{array}{l}\text { Probable } \\
\text { Probable } \\
\text { Possible } \\
\text { Definite }\end{array}$ & $\begin{array}{r}1.0 \\
16.0 \\
12.0 \\
12.0\end{array}$ & $\begin{array}{l}0.5 \\
1.6 \\
2.5 \\
3.8\end{array}$ & $\begin{array}{r}7 \cdot 2 \\
14 \cdot 7 \\
4 \cdot 9 \\
8 \cdot 8\end{array}$ & $\begin{array}{r}9 \cdot 3 \\
10 \cdot 5 \\
10 \cdot 6 \\
8 \cdot 3\end{array}$ & $\begin{array}{r}1.0 \\
11 \cdot 2 \\
15.0 \\
16.0\end{array}$ & $\begin{array}{l}1 \cdot 0 \\
0 \cdot 4 \\
3 \cdot 6 \\
3 \cdot 3\end{array}$ \\
\hline
\end{tabular}


levels of creatine phosphokinase activity in four mothers of males with Duchenne dystrophy. In three of the four, the random sample showed raised levels of activity: in all, the resting values are within normal limits.

\section{BIOPSY}

In each of the three cases where a biopsy of muscle was taken, definite pathological changes were present. These were limited to a few fibres, the remainder of the muscle appearing normal except for occasional clumps of hyperchromatic sarcolemmal nuclei, suggesting that muscle fibres might have completely disappeared. Individual muscle fibres were affected and even segments of fibres. Sometimes the myofibrils had disappeared and sarcoplasm showed a floccular change (Fig. 1). In one case, vacuolar degeneration had occurred in the centre of a swollen muscle fibre (Fig. 2). Disappearance of segments of myofibres was indicated by an occasional empty sarcolemmal tube surrounded by swollen sarcolemmal nuclei with nucleoli (Fig. 3). More often the sarcolemmal tube was packed with macrophages and no trace of myofibrillar structure remained (Figs. 4 and 5). Connective tissue stains showed that these collections of phagocytic cells were not interstitial. Two adjacent fibres might be affected with loss of striation, invasion by macrophages, and large vesicular nuclei (Fig. 6). Such changes have not been seen in normal muscle in our experience. Marin and Denny-Brown (1962) commented that, although there might be some variation in size of 10 to $15 \%$ of muscle fibres in normals, loss of cross striations, sarcoplasmic cloudy granular changes, and phagocytosis were absent.

\section{DISCUSSION}

Three of the four mothers were selected for this investigation because of elevated creatine phosphokinase activity on random sampling. The study is not concerned with the incidence of elevated creatine phosphokinase activity in the mothers of males with Duchenne dystrophy.

Previous investigations have shown that the level of creatine phosphokinase activity in the normal is not significantly influenced by exercise, although Richterich et al. (1963) reported a mild elevation after severe physical work. Thus it has been considered that in the identification of the female carrier exercise does not influence a casual estimation (Pearce et al., 1964b). Our observations confirm that in the normal exercise has no significant effect. In three of the four mothers of patients with Duchenne dystrophy it is interesting that after moderately
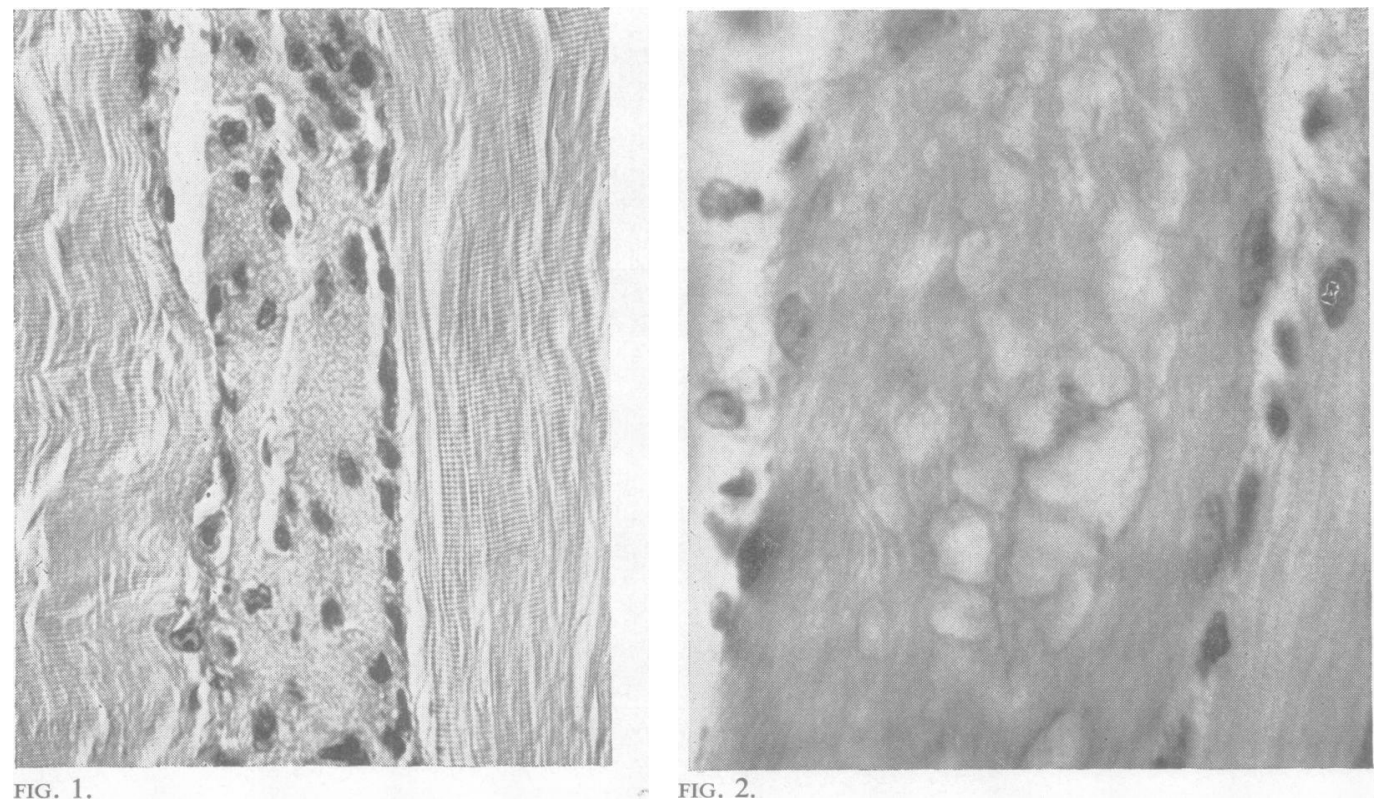

FIG. 1. Case Gu. Floccular change in sarcoplasm of single fibre with loss of myofibrils. Some macrophages are present. Picro-ponceau $\times 360$.

Fig. 2. Case Ru. A swollen fibre with loss of striations and large central vacuoles. Haematoxylin and eosin $\times 720$. 


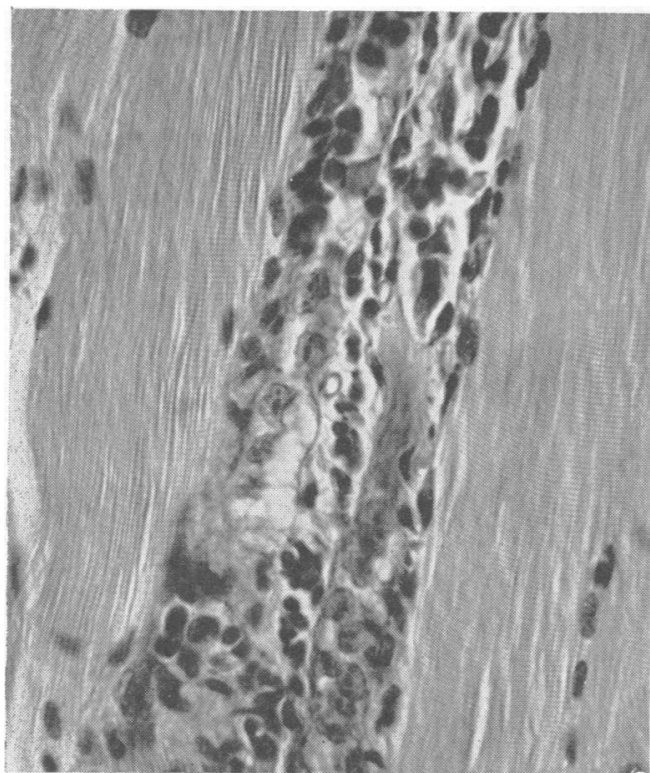

FIG. 3 .

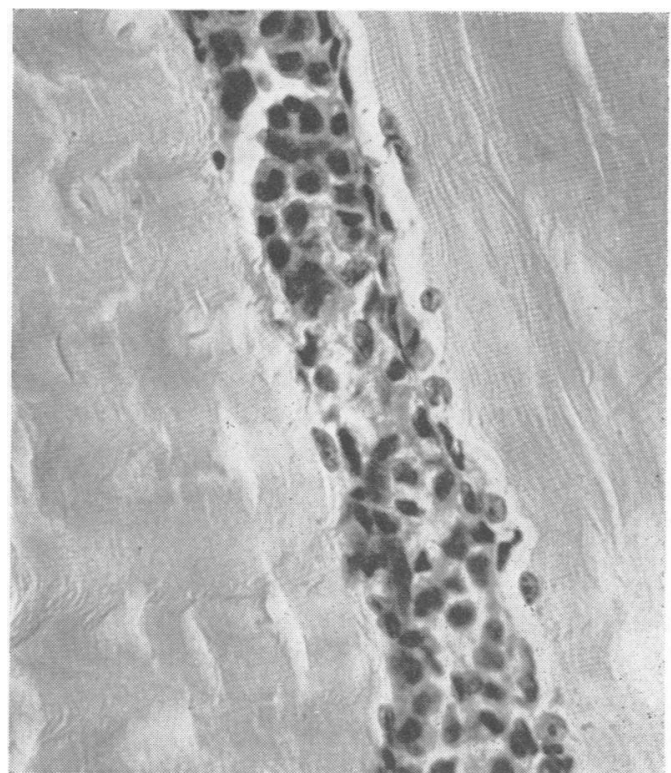

FIG. 4.

Fig. 3. Case Ru. Two fibres undergoing degeneration. The sarcolemmal nuclei are swollen and some contain nucleoli. There is extensive phagocytosis by macrophages and in one area the sarcolemmal tube is empty. Haematoxylin and eosin $\times 360$.

FIG. 4. Case Gu. Sarcolemmal tube packed with macrophages. No trace of myofibrillar structure. Haematoxylin and eosin $\times 360$.

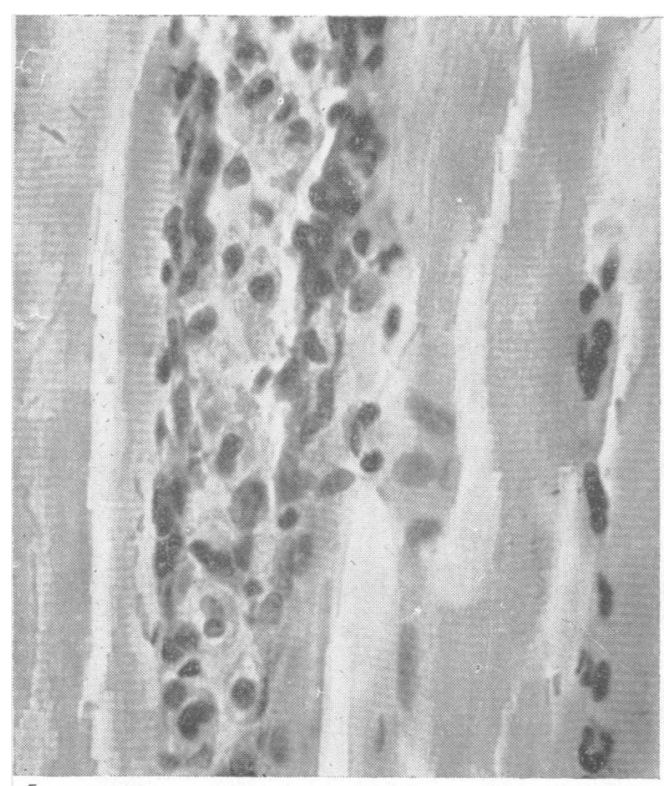

5.

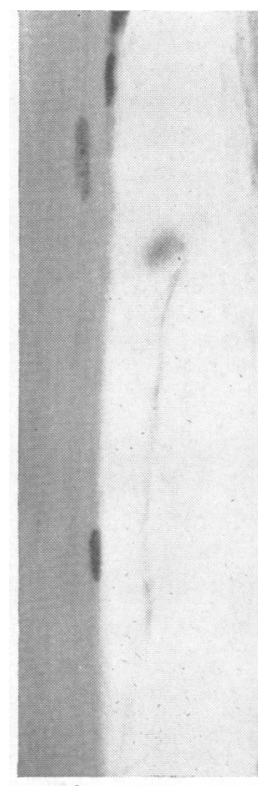

FIG. 6.

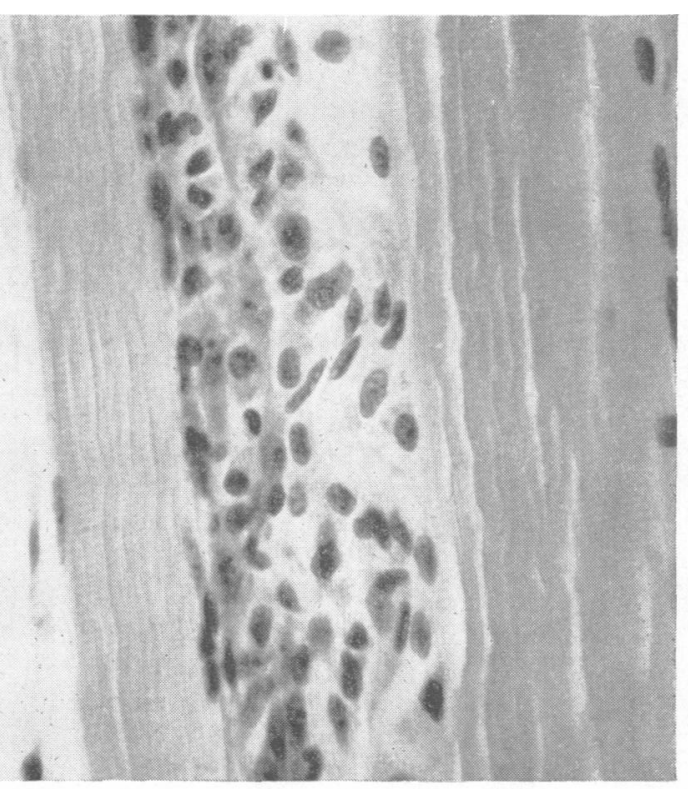

FIG. 5. Case Sch. Single fibre. The sarcoplasm is granular, there is loss of myofibrils and many macrophages are seen. Haematoxylin and eosin $\times 360$.

FIG. 6. Case Sch. Two degenerating fibres with loss of structure, invasion by macrophages, and large vesicular sarcolemmal nuclei. Haematoxylin and eosin $\times 360$. 
severe exercise, the level of creatine phosphokinase activity corresponded closely to that obtained from a random sample, this sample having been taken during normal daily activity. It would seem that the leak through the abnormal muscle membrane could not be increased by prolonged exertion above that produced by ordinary activity, giving support to the view that only a limited number of muscle fibres were abnormal and that they leaked maximally on slight muscular effort. Rest reduced the creatine phosphokinase level to normal but there was a prompt rise with exercise. Hughes' (1963) observations that the level of creatine phosphokinase activity declines with the progress of the disease confirms Pearson's work with serum aldolase (Pearson, 1962). The latter suggested that this reflected a decline in the total number of muscle fibres. An alternative explanation is that the enforced inactivity reduced the leak. In one of our cases of pseudohypertrophic dystrophy, the level of creatine phosphokinase activity at rest was 95 i.u., but after walking around the ward rose to 230i.u.

Isolated dystrophic fibres were seen in the three biopsy specimens. These were rare, and characterized by loss of myofibrillar structure, often with phagocytosis by macrophages. In one case, in addition, there were swollen fibres containing vacuoles. This histological demonstration of a small proportion of abnormal fibres lends support to the Lyon hypothesis and shows that, in the female carrier, when the serum creatine phosphokinase activity is elevated, a proportion of dystrophic fibres exists. Whether these may later disappear, thus accounting for normal creatine phosphokinase levels in known carriers, has not yet been established. It is clear that one cause of normal levels in such carriers may be the time of the random sample and this should always be taken after a period of moderate exercise.

\section{SUMMARY}

Four mothers of males with the Duchenne type of muscular dystrophy showed normal levels of creatine phosphokinase activity after a number of hours of bed rest. There was a prompt rise after standard exercise, in three cases the level corresponding closely to that obtained by random sampling during ordinary daily activity. In each of these three cases, biopsy of the gastrocnemius muscle showed isolated dystrophic fibres. It is concluded that when the creatine phosphokinase activity is raised in the female carrier of Duchenne dystrophy, a population of abnormal fibres exists and that intracellular enzymes leak into the serum on muscular exertion but not at rest. If creatine phosphokinase activity is to be used as a method of identifying the female carrier it is important that the sample be taken after a period of activity.

Grateful acknowledgement is made to Miss Alice Rudolph and Mr. Aubrey McCrimmon for skilled technical help.

\section{REFERENCES}

Dubowitz, V. (1960.) Progressive muscular dystrophy of the Duchenne type in females and its mode of inheritance. Brain, 83, 432-439.

Ebashi, S., Toyokura, Y., Momoi, H., and Sugita, H. (1959). High creatine phosphokinase activity of sera of progressive muscular dystrophy. J. Biochem. (Tokyo), 46, 103-104.

Emery, A. E. H. (1963). Clinical manifestations in two carriers of Duchenne muscular dystrophy. Lancet, 1, 1126-1128.

Ennor, A. H., and Stocken, L. A. (1948). The distribution of acidsoluble phosphates in the fatty liver. Biochem. $J$., 42, 549-557.

Hughes, B. P. (1963). Serum enzyme studies with special reference to is the Duchenne type dystrophy. In Research in Muscular $\infty$ Dystrophy, Proc. 2nd Symp., Muscular Dystrophy Group N pp. 167-179. Pitman Medical Publishing Co., London.

Lyon, M. F. (1961). Gene action in the X-chromosome of the mouse Nature (Lond.), 190, 372-373.

Marin, O. S. M., and Denny-Brown, D. (1962). Changes in skeleta muscle associated with cachexia. Amer. J. Path., 41, 23-29.

Martin, J. B., and Doty, D. M. (1949). Determination of inorganis phosphate. Modification of isobutyl alcohol procedure. Anag $\frac{1}{O}$ Chem., 21, 965-967.

Okinaka, S., Kumagai, H., Ebashi, S., Sugita, H., Momoi, H. Toyokura, Y., and Fujie, Y. (1961). Serum creatine phosph kinase; activity in progressive muscular dystrophy and neuro muscular diseases. Arch. Neurol. (Chic.), 4, 520-525.

Pearce, J. M. S., Pennington, R. J., and Walton, J. N. (1964a) Serum enzyme studies in muscle disease. Part I. Variations in serum creatine kinase activity in normal individuals. J. Neurol. Neurosurg. Psychiat., 27, 1-4.

- _ (1964b). Serum enzyme studies in muscle disease. Part III. Serum creatine kinase activity in relatives of patients with the Duchenne type of muscular dystrophy. Ibid., 27, 181-185.

Pearson, C. M. (1962). Histopathological features of muscle in the pre-clinical stages of muscular dystrophy. Brain, 85, 109-120.

- Fowler, W. M., and Wright, S. W. (1963). X-chromosome mosaicism in females with muscular dystrophy. Proc. nat. Acad. Sci., 50, 24-31.

Richterich, R., Rosin, S., Aebi, A., and Rossi, E. (1963). Progressive muscular dystrophy. V. The identification of the carrier state in the Duchenne type by serum creatine kinase determination. Amer. J. hum. Genet., 15, 133-154.

Thomson, W. H. S. (1962). Sources of error in the biochemical diagnosis of muscular dystrophy. J. Neurol. Neurosurg. Psychiat., 25, 191-202.

Walton, J. N. (1956). The inheritance of muscular dystrophy. Ann hum. Genet., $21,40-58$. 